\title{
La novel la històrica en mans de Josep Lozano: Crim de Germania i El Mut de la Campana
}

\author{
The historical novel in the hads of Josep Lozano: Crim de Germania \\ and E1 Mut de la Campana
}

\author{
M. JESÚS FrAnCÉS \\ mjfrancesmira@gmail.com \\ IES La Creueta (Onil)
}

\begin{abstract}
Resum: Parlar de la novel la històrica en la producció de Josep Lozano s'associa indubtablement a la prestigiosa obra Crim de Germania que l'autor riberenc mostrava al públic l'any 1980. Més de vint anys després reprenia aquest format per a crear El Mut de la Campana (2003) i, de nou, demostrava la seua mestria dins d'aquest gènere. L'objectiu i la configuració interna en ambdues és diferent però el que va empentar l'autor en la dècada dels 80 a usar aquesta vessant creativa tan de moda aleshores persisteix: tornar a un temps passat i contar-lo en una època actual a través del filtre de la ficció i així mostrar quina societat ha sigut i és la societat valenciana. Una societat, aquesta, que sobreïx en tot moment de les dues obres per a demostrar com funciona col lectivament, així com què la determina des d'un punt de vista idiosincràtic.
\end{abstract}

Paraules clau: novel la històrica, marc, anàlisi narrativa, etnopoètica, folklore.

Abstract: Any analysis about Josep Lozano's historical novels is undoubtedly associated to his prestigious work Crim de Germania, which the Ribera born author released in 1980. Some 20 years later he created another historical novel, ElMut de la Campana (2003), once again showing his mastery of the genre. The purpose and structure of both works are different, but what motivated the author to use such a creative format in the 80's persists today: travel back in time, and tell the story as if it were the modern day through a fictional filter and, in doing so, showing what Valencian society was like. A society, this one, which is prevalent throughout both works, shows how it works collectively as well as how it is defined by its idiosyncrasies.

Keywords: historical literature, frame, narrative analysis, ethnopoetics, folklore. 


\section{Introducció}

L'escriptor alginetí Josep Lozano s’iniciava en el món i el mercat literari amb la novel la històrica Crim de Germania l'any 1980, guanyadora del Premi Andròmina l’any 1979 en la huitena edició dels Premis Octubre, del Premi de la Crítica del País Valencià (1980) i del Premi de la Crítica Serra d'Or (1981). Aquest gènere s'emmarca dins del moviment del Romanticisme que es dona al segle XIX i que, a grans trets, valora per damunt de tot la llibertat, advoca pel subjectivisme perquè el que importa és el que sent l'individu i evoca el passat i els triomfs que s'hi donaren. És, per tant, comprensible, que dins d'aquest moviment sorgisca la novel la històrica en què ficció i història s'uneixen per a narrar fets $i$ aspectes que afecten l'individu.

En la dècada dels huitanta especialment, en l'àmbit de territori català, s'hi dona un regust per aquest gènere i les claus són, per una banda, el seguiment d'una moda, com és la de la novel la històrica, de caràcter internacional, mitjançant el messianisme de Robert Graves amb Jo Claudi (1934), de Margarite Yourcenar amb Memòries d'Adrià (1951) o el d'Umberto Eco, tot i que més tard, amb El nom de la rosa (1980). Lògicament, la repercussió d'aquestes obres als anys huitanta es deu en gran manera al fet que cap a finals dels anys setanta apareguera la versió televisiva de l'obra Jo, Claudi, feta per la BBC i emesa en català per TV3; que l'any 1983 es publicara la traducció al català de la novel la històrica de Yourcenar, realitzada per Jaume Creus; i que l’any 1986 apareguera la versió cinematogràfica d'El nom de la rosa amb el mateix títol i que també fou doblada al català.

Per una altra banda, gràcies a la novel la històrica l'escriptor pot tornar a un temps passat i contarlo en una època actual a través del filtre de la ficció de manera que l'individu, com a part d'un col lectiu, d'una societat, siga conscient de quina és la seua història. Aquesta història, en el cas de territoris subjugats a un règim dictatorial com els de l'Estat espanyol, no s'ensenyava a l'escola però calia saber-la i recordar-la. I és que durant la dictadura, l'educació estava dirigida per un nacionalcatolicisme que no tenia en compte les llengües autòctones, com ara el català, el gallec o l'èuscar; així mateix, la informació que es donava estava totalment mediatitzada; per tant, hi havia una mancança d’informació històrica i social que s'havia de conèixer.

A més, des del punt de vista narratiu, Salvador \& Piquer (1992: 28) defensen que és un model molt apte que permet mesclar un context històric i real amb un món ficcional i imaginatiu; permet connectar, parlant de la línia temporal que segueix la història, el present amb el passat, de manera que el lector és conscient de quina és la història de la qual prové; i, per últim, és un model narratiu que possibilita mostrar tota l'esplendor del llenguatge sense que aquest caiga en un arcaisme desconcertant per al lector, sent així un mitjà d'expressió intel ligible.

Aquests són els motius que van empentar en el seu moment Josep Lozano a crear Crim de Germania, la seua primera novel la històrica, ambientada en la revolta de les Germanies (s. XVI). Cal, però, recordar que Lozano sempre s'ha sentit, i així s'ha declarat, lliure de modes o gèneres a l'hora d'escriure (Tobar 2004) i encara que en el cas d'aquesta primera novel la històrica la influència 
de la moda pel gènere hi és clara, també sembla que fou una opció de l'autor per les possibilitats narratives que oferia per a vehicular el seu objectiu que no pel simple seguiment d'una moda.

En el cas concret de Lozano, l'autor tria els segles xvi amb Crim de Germania i xvII amb El Mut de la Campana -la seua segona novel la històrica, publicada l'any 2003- per a ser perpetuats en lletra impresa mitjançant aquesta forma de la novel la històrica. Immersos en plena edat moderna troba dos temes com són les Germanies -podríem dir que és un motiu mític valencià- i el fanatisme religiós en relació amb la pesta que poden posar el lector alerta a propòsit de què passava en aquests segles. Són segles que, per una banda, juntament amb el xvIII alberguen una literatura popular de gran vitalitat - per exemple, en l'àmbit de la poesia i de les cançons populars, hi havia diversitat de formes com ara les nadales, els gojos, les cançons religioses, cançons de bandolers, corrandes o cançons de pandero. És aquesta -juntament amb tota manifestació que faça referència a l'àmbit de l'etnopoètica- la que podem resseguir sense problema en les obres de Josep Lozano en general, i en les novel les històriques en particular, per tant, no és d'estranyar aquesta tria.

Però, per una altra banda, gràcies a aquest temps històric Lozano pot parlar d'un tema que els valencians sentim com una herència rabiüdament negativa, i a través de contar-la, és com si volguérem trobar la redempció col lectiva. Es tracta de la temàtica dels moriscos, de quina era la seua situació al Regne de València -com es veu en Crim de Germania-, o com fou la seua expulsió l'any 1609, tal com apareix col lateralment en El Mut de la Campana i amb una major profunditat en el relat també històric «El rei Turigi» - publicat en la Revista de la Safor l'any 2010 i posteriorment novament editat dins del recull de relats Després de les tenebres i altres narracions (2013).

Així, aquests segles demostren que l'autor riberenc té un triple objectiu a l'hora de triar-los: primer, mostrar al públic lector què va hi ocórrer - amb una funció alliçonadora clara, sobretot en Crim de Germania-; per un altre costat, donar veu a una literatura i una cultura populars extremadament riques, parts intrínseques de la societat valenciana, que necessiten ser fixades per escrit $-i$, de fet, esdevenen un dels puntals forts i permanents de la base de la seua producció-; i per últim, plasmar temes històrics tan importants per als valencians com el dels moriscos, que esdevé una preocupació de molts autors situats al costat de Lozano.

Comptat i debatut, aquest és el marc concret que envolta no només el naixement públic de Josep Lozano com a escriptor, i més concretament, escriptor de narrativa, sinó també el d’un gènere tan profitós per a ell com el de la novel la històrica. Un marc, aquest, caracteritzat per unes condicions dures, amb un passat tenebrós, però que inicià un futur amb esperances i expectatives de normalitat dins la literatura creada al territoris de llengua catalana però concretament la conreada al País Valencià. 


\title{
2. L'esclat de la novel ta històrica amb Crim de Germania
}

La presentació d'una novel la com Crim de Germania reclama unes paraules acurades i exactes. Qui millor per a fer-ho, així doncs, que el mateix autor?:

\begin{abstract}
Calia imaginar-se la necessitat d'explicar, de narrar uns fets que transcorrien en un lapse de la nostra història: l'època de les Germanies. Els inicis del segle XVI són dels quatre o cinc moments clau dels valencians com a poble. Bé, doncs, calia mostrar això davant un públic que ho desconeixia tot del seu propi passat col lectiu. Hi havia una obligació d'informar, no fins al punt que fóra erudit, però sí que hi havia una certa intenció didàctica. En els plantejaments de la novel la hi havia una necessitat d'esquematització que facilitara la comprensió, l'acostament del lector. Hi havia una exigència d'un cert maqueisme [sic] previ, que després s'anara superant per donar pas a una explicació on no hi haguera ni bons, ni roïns, i on cadascú estiguera en el seu lloc (Sorribes 1989: 93).
\end{abstract}

Amb aquestes paraules Josep Lozano dona les claus per a entendre l'obra que suposà el seu gran naixement com a escriptor: la novel la històrica Crim de Germania. Aquesta esdevenia una embranzida, un nou alè en l'encoratjada -literàriament parlant- dècada dels huitanta. Els motius són clars: era una obra que agafava una temàtica concreta, la de les Germanies a terres valencianes, per a reivindicar què és el que va ocórrer durant aquest període i, de retop, explicar -ja en el segle $\mathrm{xx}$ - què és el que havia passat amb la guerra i postguerra que visqué l'Estat espanyol a causa dels indubtables paral lelismes. L'autor, però, sorprén amb la forma innovadora amb què presenta l'obra -clarament influïda per la línia de Manhattan Transfer (1925) de John Dos Passos-a l'hora de contar de manera fragmentada i des de diferents perspectives com van viure les Germanies els diversos col lectius involucrats en aquesta contesa. Tot això embolcallat en el gènere de la novel la històrica, tan de moda en el moment de la publicació de l'obra, i que encaixava perfectament en la línia de la literatura de gènere per la qual apostaven els autors.

Les definicions que s'han fet de Crim de Germania no han sigut poques però totes tenen uns elements comuns: es tracta d'una obra que recupera, recupera història, recupera memòria i recupera una llengua pulcra i sublim. Hi ha un fragment de Pere Calders - d'una gran beutat- que deixa aquesta idea ben palesa:

\footnotetext{
Aprendre, deleitar-se [sic] o recordar? Heus ací una -vella i sempre suggerent- proposta. Si més no, el llibre ajuda a «recordar»-amb una apassionada recerca pel relat i la ficció, tambéepisodis ben colpidors i paradigmàtics de la nostra memòria col lectiva. En aquest sentit, l'escriptor argentí Ernesto Sábato, per exemple, anomenà «testimonis» els escriptors que han sentit -o senten- la necessitat oculta però incessant de testimoniar el seu drama personal o del seu poble, la seua dissort, la seua lluita o les seues esperances (Garcia 1997: 35).
}

La història de Crim de Germania és transmesa d'una manera original: és una obra coral que comença pel final del moment històric que s'hi plasma, amb una clara venjança particular alhora que col lectiva 
per part de l'autor sobre un personatge històric de la talla d'Úrsula Germana de Foix, sotmés a la venjança dels agermanats ajusticiats. Per tant, aquest panorama que es presenta des de bon inici necessita de la resta de l'obra per a fer entendre els motius de la revenja referida.

La varietat de personatges -tant històrics com ficcionals- està en un primer nivell esbiaixada per la divisió entre els dos bàndols implicats en la lluita: agermanats i mascarats. Tanmateix, un repàs per aquests ajuda a entendre quins són els fils que mouen la trama.

La virreina Úrsula Germana de Foix en el capítol titulat «El banquet» es configura com un personatge redó, complex, que evoluciona al llarg del relat sucumbida pels efectes de la por -i del desig-cap a uns enemics que retornen del regne de la mort per a endur-se-la subtilment. La mort esperpèntica amb què Lozano castiga aquest personatge i on la fantasia i l'onirisme arriben al seu clímax no contradiu, però, el caràcter referencial del personatge en qüestió: «Fins que reina i mosquer fou mort, mort en la mort, os esblanqueït, maceria de cantal, mosquer de mosques» (Lozano 2006: 46). Certament, com que es tracta d'un personatge fàcilment identificable pel lector mitjançant el seu coneixement enciclopèdic, sembla estar més condicionat en les seues accions que els personatges inventats. Malgrat això, com afirma Salvador, aquesta mena de personatges poden realitzar «de vegades, accions que consten com a històricament documentades $i$, altres voltes, responen a la fantasia imaginativa del novel lista; però sempre [...] s'insereixen en la lògica del marc històric que els condiciona i fins i tot els explica» (2001: 64).

De fet, i ja més concretament sobre el personatge de la virreina, el mateix estudiós apunta:

Germana, en canvi, personatge històric com és, mor d'una mort inventada per l'autor i determinada pel caire màgico-oníric del conte en què apareix: la veritat històrica de la seua fi no rau en la circumstància concreta sinó en el significat profund de l'odi que la seua política repressiva va generar i que l'autor, segles més tard, ressuscita (2001: 65).

En el segon i tercer capítol, canvia el personatge principal, de manera que passem d'una figura femenina, posicionada en el bàndol reial i de caire real, a una figura masculina, del bàndol dels agermanats i amb un caràcter entre real i llegendari. Es tracta del personatge d'«El rei Encobert» nom que dona títol al primer dels dos capítols-, que amaga la identitat d'Antoni Navarro, anomenat l'Encobert per anar fugint amagat de la Inquisició.

Al llarg de dos capítols veiem la configuració que fa Josep Lozano d'aquesta figura, el qual exalça a la categoria de mite. Com a personatge dinàmic i redó que és, en el segon capítol veiem confirmades les característiques -inclosos els dons de caire més fantàstic- que ja es mostraven en el primer però amb un tarannà més propagandístic gràcies al format dels sermons. Antonio Navarro queda definit com un personatge estrambòtic, visionari i sobretot persuasiu, que no va poder fer reviscolar la revolta de les Germanies però va fer que la història dels valencians el recordara com una llegenda. Bona prova és la ironia amb què Lozano el dota ja que, tot i mort, es riu de tots aquells que 
l'observen, perquè els seus enemics poden matar-lo però no esborrar-lo de la memòria col lectiva. Sembla que Lozano vulga tornar a aquest personatge el lloc que es mereix dins de la trajectòria dels valencians i palesar així quins són els seus mites.

Ara bé, si fins ara els capítols s'han centrat en un personatge concret, el quart apartat de Crim de Germania no n'observa un només sinó diversos mitjançant els ulls escrutadors de la Inquisició. «Transcripció d'algunes fitxes personals» és el títol que dona pas a una sèrie de fitxes, com una mena de fitxes policials - concretament tretze- realitzades, ja s'ha dit, per la controladora Inquisició sobre diferents personatges que intervenen en la revolta de les Germanies. Els personatges fitxats són tant del bàndol dels agermanats com del bàndol dels mascarats -tot i ser el mateix que el de la Inquisició- i s'aporta una informació ben exhaustiva a propòsit de les seues dades personals primer i segon cognoms; nom; nom i cognoms del pare i de la mare; germans i germanes-; el seu ofici; el seu estat civil i, en cas d'estar casats, qui és i quin ofici desenvolupa; el sexe al qual pertanyen (masculí, femení o dubtós); els càrrecs que ostenten; els viatges fets a l'estranger; els trets físics que els caracteritzen; quina és l'educació rebuda; les llengües que dominen; els altres noms amb què són coneguts; les referències que hi ha sobre el caràcter o la forma de ser; la ideologia que professen; la valoració dels personatges segons la Inquisició; els amants que tenen; quins són els seus gustos personals, així com es remarquen «altres punts» d'interés. ${ }^{1}$

Amb aquestes fitxes l'autor, d'un colp, fa que el lector conega cadascun dels personatges en qüestió, sense haver d'aprofundir-ne més posteriorment. Segons Piquer «el narrador presenta els personatges que intervenen en els relats i s'estalvia de repetir les predicacions més elementals sobre els actors de les seues històries» (1997: 25). Així doncs, podem dir que estem davant d'un capítol coral -dins de la coralitat que suposa la novel la completa-malgrat que sí que hi ha un únic focus observador: el de la Inquisició. D’aquesta manera les fitxes estan unificades per dues vies: per fer referència a personatges sotmesos al seguiment de l'esmentada Inquisició i perquè aquests personatges formen part de la revolta de les Germanies d'una manera o una altra.

Com ocorre en aquest darrer capítol, «El debat» també recau sobre els muscles de diversos personatges històrics, en aquest cas de tot un col lectiu: els agermanats. Planteja la discussió que té lloc entre els caps dels agermanats sobre si acceptar o no la proposta del virrei Diego Hurtado de Mendoza: cessar dels seus intents de rebel lió i ell, a canvi, intercediria per ells davant del rei perquè no els empresonara. La peculiaritat d'aquest col lectiu com a protagonista és que des de l'inici hi ha una diversitat d'opinions al seu si. Per una altra banda, el capítol següent d'«El dia de la sang», és interessant perquè mostra l'altra cara de la moneda ja que s'interna en el caràcter dels mascarats, i sobretot del virrei, així com se centra en què els du a fer batalla contra els agermanats. L'atenció en la figura del virrei lleva protagonisme al col lectiu, malgrat que la seua actuació condiciona la del virrei.

\footnotetext{
1 En la primera edició de l'obra (1980) les fitxes no arreplegaven tants punts de comentari però en l'edició de 2005 aquests augmenten i, fins i tot, se n'afegeixen més sobre elements que formen part de l'esfera íntima dels personatges. Aquest canvi pot respondre a l'afany de minuciositat pròpia de l'estil de Lozano.
} 
Dos capítols, aquests, que juntament amb el de «La mort de Vicent Peris» són els que tenen més càrrega bèl lica i històrica de la revolta. Pot ser per això la sensació que transmeten en general -menys en el d'«El dia de la sang»- és que s'ha deixat més de banda la ficció en pro d'una explicació detallada i massa exhaustiva que bandeja els plaers de la literaturització. De fet, Josep Iborra assenyalava que per a ell «El debat» «és la part menys reeixida» perquè no està suficientment treballada des del punt de vista literari (1980: 39). Així mateix, Garcia critica, en part, aquest capítol ja que, al seu parer,

\begin{abstract}
Aquesta, possiblement siga la part més lenta, on la llargària i la profunditat dels parlaments dels diversos bàndols agermanats la fan excessivament recarregada, la qual cosa no lleva que la seua incorporació fóra del tot necessària per comprendre com pensaven, sentien, concebien i actuaven les bases burgeses i populars -no mai exemptes de contradiccions, desesperances $\mathrm{i}$ clams de llibertat, propis, si més no, de la condició humana (1997: 41).
\end{abstract}

Tanmateix, tots aquests apartats, tal com diu Garcia, tenen la seua importància dins de l'engranatge de Crim de Germania.

De fet, cal esmentar que fins ara hem anat veient el personatge de Vicent Peris de manera puntual en els capítols comentats, tot i que en el relat de «Transcripció de les fitxes personals» sí que és cert que se'n fa una radiografia més exhaustiva -tots aquests fets ja certifiquen la seua importància. Malgrat això, és en el següent capítol, el de «La mort de Vicent Peris», on el veiem actuar i evolucionar especialment mitjançant el monòleg que fa en els moments previs a ser assassinat pels mascarats. El cabdill dels agermanats s'estableix, així doncs, com el gran protagonista d'aquest capítol, ja que tot aquest va dirigit a narrar com se succeí la seua mort, com ja s'anuncia al títol.

Fins ací, hem repassat els personatges històrics que farceixen Crim de Germania i que esdevenen puntals de l'obra. Tanmateix, el mosaic creat per Lozano no s'entendria sense altres personatges, també molt rellevants, però de caràcter ficcional. Talment com passava amb el capítol inicial, el primer dels personatges d'aquesta naturalesa és una figura femenina i així ho reflecteix el títol del capítol corresponent: «Documents sobre la Corbina». Segons la disposició que feu Lozano de les parts que integren la novel la, entre aquest i el capítol precedent, «Transcripció d'algunes fitxes personals», existeix un lligam que els connecta i dona sentit al fet que apareguen junts: sobre els dos planeja el tema del poder de la Inquisició, sempre a l'aguait. ${ }^{2}$ En «Documents sobre la Corbina» el narrador-autor-historiador ens presenta com a documents històrics uns textos trobats a l'arxiu de Xàtiva sobre una esclava negra, anomenada la Corbina. Aquesta era acusada per la Inquisició de nigromàntica i de col laboradora de la causa agermanada, de manera que s'aporten diferents textos -que viatgen de la prosa a la poesia- en què s'inclouen testimonis dels seus acusadors -els seus antagonistes concrets-, dels seus amants o d'ella mateixa sobre les pràctiques que feia.

2 Garcia explica que la part centrada en la negra Corbina «enllaça amb l'anterior [sobre les fitxes] a partir del procés inquisitorial. I dóna forma a una altra forma d’intransigència, ara la religiosa, adés la politicomilitar» (1997: 41). 
Però si aquest personatge ficcional de la Corbina és perseguida per la Inquisició, altres tampoc s'escapen d'acusacions i ultratges. La lluita que es mostra en l'obra entre ambdós bàndols, implica - o sobretot retruca- a certs col lectius que podríem situar sota l'etiqueta de víctimes de la Germania. Lozano centra la seua atenció en uns personatges marginats socialment -un tret propi de la seua producció- que esdevenen víctimes per sofrir les intransigències i les atrocitats que tota guerra, malauradament, comporta. Ens referim, en primer lloc, al col lectiu dels moriscos. Els capítols nové, «Memòries de Felip Quzman», ${ }^{3}$ i desé, «El Senyal Evident o la Prova Clara» -relat que Lozano incorpora a Crim de Germania en l'edició de 2005-, se'n fan eco.

El primer dels dos relats és un relat autobiogràfic contat i protagonitzat per Hassan ibn Ishaq Ahmad al-Aslami, morisc d'Oriola que es veu obligat a adoptar el nom cristià de Felip Quzman i amagar, així, la seua identitat. A pesar de ser un personatge individual representa tot el col lectiu dels moriscos, de manera que té aquesta doble vessant. La seua veu $-i$, per tant, la dels moriscospren el mateix to i la mateixa intensitat que la dels agermanats, ja que totes dues reivindiquen un poble que és privat dels seus costums, de la seua llengua i, fins i tot, de la seua religió en aquest cas. ${ }^{4}$ Tanmateix, en aquest capítol es mostra com aquells agermanats que es consideren víctimes d'una situació injusta -i, per això la revolta- es tornen botxins. Es veu, així doncs, des d'una altra perspectiva la mateixa opressió del poder.

Quzman es planteja, en definitiva, com un personatge del qual el lector coneix tota la seua evolució vital i, a més, d'una manera propera - proximitat que facilita la primera persona del jo narratiuestablint-se com un personatge redó en tota la seua plenitud. A ulls, per tant, d'aquest lector s'erigeix com un supervivent davant les adversitats amb què s'enfronta.

De l'altre capítol esmentat, «El Senyal Evident o la Prova Clara», Vicent Salvador, en el pròleg de Laodamia $i$ altres contes -recull on es publicà primerament el relat en qüestió-, explica que «ens retorna al món de les germanies, on Lozano es mou com peix en l'aigua, per a explicar-nos la història d'una singular venjança» $(1986,13)$. Efectivament, en aquest relat se'ns conta com el morisc Çaad Algazel ordeix una estratègia per a venjar la mort de son pare i de tots els seus iguals, ja que finiren a traïció a mans dels agermanats. Aquests, després de ser convertits al cristianisme en un baptisme massiu, van ser degollats al castell de Polop com a càstig per la notícia que arribà al capità Peris sobre la possible ajuda que alguns moros havien demanat a Xirles per tal que atacaren els agermanats. Així, el pacte que el cabdill havia acordat amb ells el trencà sense miraments.

3 Segons Josep Iborra (1980: 39): «L'aventura d'aquest morisc -subjecte d'un altre "crim"- ens permet veure aquella història amb els ulls d'un musulmà que ens revela aspectes de la vida quotidiana d'una València en què un, circulant pels carrers, podia trobar-se amb un home penjat...».

4 Recordem les paraules de Gregori sobre el relat «El rei Turigi»: «Malgrat que l’època històrica en què se situa l'acció és pràcticament la mateixa que la que trobem a El Mut de la Campana, en realitat, El rei Turigi es troba molt més a prop de la perspectiva i de les reflexions contingudes a Crim de germania» (2013: 10). 
Queda clar que el personatge de Çaad Algazel compta amb un món interior ric i no exempt de complexitat: a l'inici, entre l'estupefacció del genocidi i la visió de la testa de son pare, dubta de si venjar totes aquelles morts però instantàniament canvia de parer. Es posa com a meta aconseguir que tot allò que havia sofert el seu poble -a mans dels que precisament lluitaven per tindre també un poble propi i lliure- no podia quedar impune. D'aquesta manera es configura com un personatge redó en tant que passa per diferents estats d’ànim que van des del menyspreu i la confusió inicials, a l'alegria per una possible venjança, la ràbia posterior, i tot seguit la calma abans de la decisió ferma i final de dur endavant la venjança.

Aquesta imatge dels defensors de la Germania s'allargarà fins a cloure l'obra perquè també es troba en el darrer capítol titulat «Lletres a l'absent». El motiu és perquè hi ha un nova perspectiva de les Germanies, malgrat que com ocorria en els dos capítols precedents, és la perspectiva d'unes altres víctimes del moviment: els homosexuals. Mitjançant l'epístola mossén Adrià conta com la relació amorosa i sexual que mantenia amb un home, forner de professió, acaba perquè els descobreixen. Els càstigs foren diferents per a cadascun: a mossén, gràcies a amics que tenia dins de l'Església, l'enviaren a l'exili; i a l'amant, en canvi, el cremaren a la foguera. Així, a través de cadascuna de les cartes -llevat d'una, que no l'escriu el clergue sinó que la rep de la seua família- mossén Adrià es lamenta del que els va ocórrer, enyora el seu amant i, això sí, defensa el seu amor, un amor, aquest, que no perjudicava ningú però que els agermanats condemnaren a mort, en clara consonància amb el que exigia l'Església. El tema, per tant, «ja no és la revolta popular, ni la causa perduda dels moriscos, sinó la d'un capellà que atemptà contra els sagrats vots de l'Església Apostòlica i Romana» (Garcia 1997: 43).

El protagonista principal d'aquest capítol és, sens dubte, mossén Adrià, que amb el vehicle de l'espístola es revela com un personatge redó, amb un món interior ben contundent. Ens conta quin ha sigut el seu crim: estimar un altre home, un fet condemnat per l'Església i per la Germania., com hem dit. Gràcies a les cartes extraiem informació de les Germanies però sobretot trobem la visió d'un home homosexual desterrat per ser precisament fidel a ell mateix i no a un poble o a una religió, tot i ser clergue. Advertim, així doncs, com l'obra comença i acaba amb la temàtica del crim: en el primer capítol era el crim que va dur a terme Úrsula Germana de Foix amb la mort de tants agermanats; i en l'últim tenim la contrapartida del crim realitzat ara pels agermanats contra una parella d'homosexuals.

Són aquestes veus marginades les que han de tindre una consideració especial, tant per la seua conformació (el fet de perfilar i mostrar la psicologia de personatges com Felip Quzman o mossén Adrià), com per la seua significació moral i ètica.

Ara bé, tant uns com altres personatges es caracteritzen per una configuració complexa, rica en matisos, a banda d'emmarcar-se tots els en l'espai que ofereix el Regne de València, amb un predomini absolut de la ciutat de València com a macroespai, dins d'una època en particular com és el segle XVI, concretament de l'any 1519 al 1527 -malgrat no seguir l'obra un ordre lineal. És 
indubtable, així doncs, que tot aquest marc espaciotemporal col labora en la unitat de l'obra ja que per a parlar d'un tema (les Germanies) que reclama unes coordenades concretes, cada part juga amb aquestes coordenades amb una absoluta coherència.

I hem dit que aquests personatges tenen veu, però ara afegim que és una veu propiciada pel format: la fragmentació de la novel la en capítols o relats els dona oportunitat de dir el seu propi punt de vista i fer que el multiperspectivisme puga aclarir moltes qüestions.

La pretesa imparcialitat de l'autor que flaqueja a nivell general per posicionar-se, indiscutiblement, a favor del bàndol popular, no obnubila la mirada més negativa dels agermanats en relació amb el seu atac frontal contra moriscos i homosexuals, o el tarannà divers dins del bàndol contrari, el dels mascarats. Aquesta polifonia de veus també dona pas a una amalgama de narradors, que de vegades es mantenen externs $i$ altres assumeixen la veu dels protagonistes $\mathrm{o}$ altres es queden en una mena de llindar, com li ocorre al narrador-autor-historiador que s'encarrega de donar autoritat a la documentació consultada. Una documentació, aquesta, que aporta realisme o, millor dit, versemblança a l'obra. Però l'originalitat de la novel la també ve per la via de la intertextualitat, fruit, en part, de la constant tasca de documentació que du a terme Lozano per a poder llançar-se sobre segur a crear ficcionalment. Aquesta tècnica posa a prova el lector, tant per si és capaç de reconéixer-hi les referències (per exemple, els paratextos que encapçalen els capítols) o els estils (el realisme màgic d'«El banquet», l'escriptura picaresca en «Memòries de Felip Quzman» o l'escriptura ovidiana en «Lletres a l'absent», per posar uns exemples), com si pot seguir l'esforç que suposa llegir l'obra tenint en compte tots els components.

\section{Una segona aposta per la novel la històrica: E1 Mut de la Campana}

Un segle més tard, el XviI, és també retratat per Lozano amb El Mut de la Campana (2003) que si ja no té la intensitat identitària i didàctica de l'esmentada Crim de Germania-pensem que es publica més de vint anys després que aquesta- no deixa de perseguir el retrat d'una societat valenciana acudint a un segle convuls.

Bernat Crestalbo, amb vora cinquanta anys, conta al lector quina ha estat la seua vida en què un fet capgirà el seu rumb. Com a protagonista de la novel la esdevé un personatge intricat, afectat fins a sucumbir per les imposicions socials i religioses d'aquesta època virulenta. Així, es culpa per la pesta que sobrevingué la societat valenciana a causa de la seua actitud luxuriosa: ell, religiós de l'orde de Predicadors, manté una relació amorosa i passional amb Constança, representant de la vida llibertina. L'autocàstig que s'infligeix, per tant, tallant el seu membre viril, està a l'altura de les circumstàncies.

L'origen del nom de Bernat ja es relaciona amb el món de la religiositat, concretament amb la batalla entre musulmans i cristians i la conversió dels primers en els segons, encara que aquesta 
vegada no a causa de la violència sinó per una força suprema: la divina. Veiem, per tant, amb aquest detall la pacient tasca que desenvolupa l'autor Josep Lozano a l'hora de filar tota la trama com una gran xarxa de relacions, des del primer repunt fins a l'últim.

El tret que millor defineix el protagonista i que ja hem anat avançant és el seu desig per les dones. Aquest desig es materialitzarà amb la relació passional mantinguda amb Constança, una relació de la qual sorgirà una criatura que mai arribarà a nàixer per la mort prematura de la mare a causa de la pesta. Però abans d'aquesta relació, Bernat viurà dos encontres amb dues dones que sense que arriben a culminar en una relació sexual suposen el preludi de l'afer amb Constança. Tanmateix, la gran càrrega negativa que el protagonista atribueix als actes que comet en relació amb les dones no només ve motivada per l'ofici de religiós que desenvolupa i tot el que això comporta, sinó també perquè es fa eco de tota una tradició d'animadversió cap a les dones. ${ }^{5}$

Al voltant d'ell apareixen personatges diversos pels quals també se sent afectat. Ara bé, no tots tindran la mateixa importància, sinó la importància que Bernat els atorgue. I és que aquest personatge serà alhora el protagonista dels fets, qui els veu i també qui en parla. Per això, l'estudiós Simbor apuntava:

el lector rebrà tota la informació filtrada a través d'aquesta mena de càmera humana que és el personatge de fra Bernat. El narrador és identificat amb aquest personatge, de manera que només coneix el que ell pot saber. Dit amb altres paraules: tota la informació arribarà al lector matisada per la font de transmissió (els filtres emocional i ideològic de fra Bernat acoloriran obligatòriament de manera subjectiva la captació i la relació dels fets) i, encara més, el lector es veurà obligat a ignorar allò que és desconegut per al personatge-narrador o que aquest preferesca ocultar (2007: 18).

Per tant, és ell qui introdueix a la resta de personatges que modifiquen la seua trajectòria vital, ja siga en major o menor mesura. Com sa mare i Constança, contràries entre si i que, per tant, li mostren una perspectiva molt diferent de la vida; la seua antagonista, la Monya, que no deixarà de jutjar-lo i condemnar-lo; o el Mut de la Campana, un orat que li adverteix des del primer moment -i no erra en aquest sentit-, que la seua perdició serien les dones i així ho confirma ell mateix al final-tancant per tant el seu paper, anunciat deliberadament des del títol.

La gran ambició de Bernat de ser inquisidor i, per tant, de comptar amb tots els beneficis d'aquest càrrec es pot posar en contacte amb el triangle en què viu immers. Es tracta d'un triangle amorós que compta amb la col laboració de dues dones, tot i que amb cadascuna és un amor diferent. Com és lògic, el protagonista és el vèrtex principal i la figura geomètrica es tanca mitjançant el vèrtex que representa sa mare -amb qui manté un amor maternofilial- $\mathrm{i}$ el vèrtex oposat que representa

5 Aquesta assumpció per part del protagonista és una mostra més de la versemblança que Lozano vol aplicar a l'obra. Així, no parlarem del concepte de misogínia que respon més a una interpretació actual de totes aquestes mostres sinó d'una crítica cap a les dones que s'arrossega al llarg dels segles com una característica social. Vegeu Francés (2014: 189-191). 
Constança -qui suposa el seu amor passional i carnal. Tot el que vol aconseguir Bernat com a inquisidor és el que fa feliç sa mare des que era un infant però és un objectiu que, en canvi, no aconseguirà per la intercessió de Constança en la seua vida.

Aquestes dues dones esdevenen, per tant, dos pols oposats que fàcilment podríem posar en paral lel a la comparació que feia el personatge de fra Damià entre la Mare de Déu, encarnada per Martina Baixauli, i la seua contrincant, Eva, encarnada per Constança. De fet, aquestes són presentades -de manera indirecta, com ja s'ha dit, a través de Bernat- amb els atributs d'una i de l'altra. La mare de Bernat és introduïda en l'obra com una dona quasi angelical: «dona d'altura mitjana, pell blanquinosa, ulls blaus, ametlats, de cabells llisos i negres, poques lletres i molta virtut i humanitat» (2003: 11). Ella és el puntal de la seua família perquè no només és la que treballa per a mantindre els fills i l'home que tot ho gastava en el joc i les dones, sinó que, a més, demostra misericòrdia d'aquest darrer quan després d'abandonar-la per una altra dona torna malalt i ella el cuida fins a la mort. És una dona preocupada pel futur dels seus fills, especialment de Bernat, en qui veu possibilitats de fugir d'aquell origen humil que ella tan modestament li havia proporcionat. Aquest futur de Bernat s'encamina cap a la vida eclesiàstica, una vida que es relaciona amb l'actitud tan religiosa que Martina Baixauli evidencia en tot moment - «dona de bé, de sòlida pietat i gran exemple; devota de la Mare de Déu del Roser, de comunió de diumenge i festa feriada, i missa diària» (2003: 25)- i que s'accentuà amb l'abandonament per part del seu marit. Ara bé, Martina Baixauli no està exempta d'ambició ja que, en comprovar la capacitat retentiva del seu fill, mou cel i terra per intentar fer-li un lloc en el món religiós.

Constança, en canvi, és el desig personificat de Bernat, és la dona amb qui ell arriba a l'acte sexual i passional, de manera que esdevé el tercer dels vèrtexs del triangle que havíem esmentat adés i el desencadenant del rumb alternatiu que agafà la vida de Bernat. Com ja s'ha apuntat, aquesta podria ser posada en paral lel, segons la visió catòlica que inunda l'obra, amb la primera dona de la humanitat: Eva. La connotació de pecadora és, per tant, evident, de manera que l'oposició de Constança a la mare de Bernat és del tot clara, tant per ser el desig personificat de Bernat i, axí, la causa de la seua perdició, com per representar uns valors ben allunyats dels que promovia l'església catòlica a pesar de ser cristiana.

Ell mateix les valora en paral lel i a pesar que a l'inici del seu recorregut vital la balança s'inclinava a favor de les idees maternes sobre la vida i la religió, al final, la balança no es decanta però sí que accepta la perspectiva de Constança. Precisament arriba a aquest judici quan parlava amb ella de la pesta i de la por a la mort. Constança li contesta sense la més mínima preocupació amb quins ungüents es llavava per a prevenir-la i conclou: «Què puc fer més? Sé que la mort vindrà quan haja de vindre, però mentrestant hem de viure. Que una me'n toca i serà la meua» (2003: 230). Aquest final no tardà en arribar, igual que li passa a Martina, ja que totes dues moriran abans que Bernat. La mare per motius de vellesa i Constança a causa de la pesta, de manera que Bernat queda sol però impregnat de l'essència d'ambdues: de la mare li queda el sentit de la religiositat que li fa carregar 
amb una gran culpa pels pecats comesos; i de Constança li queda el record dels moments en què s'uniren i s'estimaren, un bon record que, per contra, serà el que li faça carregar amb l'esmentada culpa que sent.

Per una altra banda, l'amalgama de personatges que envolten aquest jo narratiu de Bernat Crestalbo es pot acarar amb una primera parada en els antagonistes, on preval el paper de la Monya, ja citada adés. Aquest malnom atribuït per la poca cura i neteja que duia del seu aspecte físic i que casava amb la imatge d'orada i captaire, amagava el de Carmeta Lareyna, una figura del baix poble valencià.

Se'n destaquen dues característiques d'ella que ben bé poden estar relacionades: el fet que de vegades parlava amb molt de seny «de tant en tant, quan li acudia el seny, parlava sofísticament, tot fent figures amb aparença de veritat i raons ben dispostes» (2003: 63) - i que demostrava intel ligència - «entre les germanes de la seua religió, havia fet mostres de gran intel ligència» (2003: 65). És per això que quan es dedica a acusar persones, en especial Bernat, o quan fa prèdiques sobre la vinguda de la pesta, la gent l'escolta amb molta atenció com si de paraules certes es tractara. De fet, en el cas de Bernat no s'encaminava malament en les seues acusacions.

Però si hem de parar atenció en un personatge i que, a més, prové de la família del protagonista, és, sens dubte, en el seu avi, Hilari Baixauli. La seua figura esdevé un referent i una gran companyia per a Bernat en aquells anys de formació i, entre tot allò que el caracteritzava sobretot cal destacar dos trets. El primer és la visió que mostrava dels moriscos. Bernat explica abans d'endinsar-se en la relació que mantenia amb el seu avi: «Ma mare em contava que Alèdua tenia cent trenta cases quan ella era xiqueta, en gran part de moriscos o cristians nous, i que després de l'expulsió del 1609 tot just en quedaren habitades una vintena de famílies» (2003: 76). És gràcies a l'avi que s'hi dona una visió amable i positiva d'aquest col lectiu dels moriscos. Així, Bernat comenta a propòsit del que li deia el seu avi:

\footnotetext{
la vida que havien dut els moriscos que habitaven aquelles terres, als qui crec que, fins i tot, tenia un cert afecte, cosa ben insòlita en un cristià. Deia que eren hòmens com nosaltres, pobres i condemnats, des de la naixença fins a la mort, a deixar-se la pell treballant, tot i que, això sí, tenien una altra religió, i no era la vertadera (2003: 79).
}

De fet, s'hi insereix l'anècdota d'un morisc, Turigit, proclamat rei després de l'expulsió i que va ser condemnat a mort amb la posterior humiliació totalment impregnada de crueltat.

Enmig de la història de nou s'insinua la bondat dels moriscos quan es conta que aquest havia mort «en donar-li garrot d'amagat - per intercessió de frare Català, que el coneixia i no volia que patís $\rightarrow$ (2003: 79-80). Cal apuntar que sobre aquest col lectiu ja parlava el mateix Josep Lozano en la novel la històrica predecessora, Crim de Germania, com ja hem vist, on també trobàvem un tractament positiu envers aquests -això sí, per part de l'autor- sense que això obnubilara la realitat que van patir a mans dels cristians. 
Però si deixem de banda aquest tema, adés hem de dit que de l'avi de Bernat se'n destaquen dos trets i el segon és el de l'advertiment. I és que després de la visió de la masovera Cecília banyant-se, quan Bernat torna a casa és sotmés a un interrogatori per part de l'avi, el qual li diu que creu que no serà un bon religiós, de manera que trobem el determinisme en joc, «Ja que pensava que, per poc que t'assemblasses a mi, que alguna cosa en deus tindre, aqueixa vida d'oració i castedat no t’acoblaria massa... M'enganye?» (2003: 82).

En relació amb aquest aspecte, el de l'advertiment, trobem també un altre personatge molt rellevant: el Mut de la Campana. En desconeixem un nom propi a pesar que aquest malnom és del tot identificatiu, ja que era un personatge mut que es comunicava a través d'una campana. Aquest ja no és família directa del nostre protagonista però, per contra, sí que és un personatge familiar per a ell, ja que apareix al llarg de l'obra sempre a mode d'advertiment. Dins de l'esgraó del poble, el Mut es trobaria en el grup encara més inferior ja que és classificat com un orat -parlem, per tant, d'un marginat-i per això resideix a la casa dels Orats.

El so de la campana del Mut -mut a causa del tall que li van proferir a la llengua per «parlar» més del compte- apareix intermitentment des que Bernat inicia la seua relació sentimental amb Constança com si fora una mena de recordatori dels pecats que ha dut a terme i la consegüent culpa que té. De manera que, per exemple, després del seu primer encontre amorós, una vegada estava a la cel la, el frare diu: «vaig sentir, o així m’ho va semblar, la dringadissa d'una petita campaneta, molt difusa, llunyana, que vaig associar, de primer antuvi, a la del Mut, com si m'avisàs una altra vegada d'algun perill» (2003: 207). Com que Bernat no entenia o no volia entendre el consell que el Mut li llançava per via acústica, la relació acabà, com ja s’ha comentat adés, amb la mort d'un dels amants a mans de la pesta: Constança. No és debades tampoc que Lozano li done al Mut l'ofici d'arreplegar els morts de la pesta i dur-los a les fosses.

Efectivament, aquest personatge no l'abandonaria fins a l'últim moment. La seua funció d'advertència arribava al final. En un inici es negava a carregar el cadàver però després acceptà a canvi de veure qui era. És en aquest punt que els lectors ens adonem realment que tant conscient era Bernat dels advertiments que li enviava el Mut, com el mateix Mut ho era de la seua comesa. Així, el nostre protagonista explica: «Després va mirar-me amb commiseració, amb llàstima, i va persignar-se bruscament, mentre jo abaixava l'esguard de vergonya, per no mirar-lo» (2003: 282).

Comptat i debatut, l'univers narratiu d'ElMut de la Campana pel que fa als personatges esdevé complex i alhora ric per la diversitat que hi ha, encara que tan sols hem destacat aquells més rellevants. $\mathrm{Al}$ voltant del nucli central que esdevé el protagonista gravita la resta d'aquests personatges. A pesar de la seua importància, Bernat Crestalbo reclama de la resta perquè la seua configuració es desplegue a ulls del lector amb totes les matisacions pertinents.

Ja hem dit que aquesta obra se situa en el segle XVII, concretament entre els anys 1610 i 1660, i novament el cap i casal hi esdevé l'espai predominant, tot i les al lusions a altres indrets del Regne 
de València. Els espais religiosos en concret no deixen d'aparéixer al llarg de tota l'obra conformant no sols el mapa conventual de València sinó els moviments del protagonista i l'avançament de l'acció. Cada espai té la seua importància en l'esdevenir de Bernat, especialment la cel la que serà el seu espai personal, el qual el veurà nàixer com a frare però també morir com a tal.

Aquesta època del segle XVII en el seu conjunt condicionarà la vida del protagonista que és alhora narrador. La forma autobiogràfica és emprada en aquest cas com el vehicle que du endavant la trama, de manera que entre el jo narratiu -tant del gust de l'autor- i el lector es crea una major proximitat, la qual augmenta la vivesa dels esdeveniments així com el joc de seducció. Aquesta forma resulta ser, per tant, un vehicle adient i contundent, i se situa al costat d'altres tècniques que afecten la forma de l'obra tals com les anticipacions de fets futurs; però també l'aparició de la intertextualitat; o les pauses que aporten sobretot les descripcions i que denoten un lirisme exultant quan es tracta de descriure a Constança, per exemple, un lirisme disseminat també al llarg de l'obra. I és que, aquest tret del lirisme és un element que es manifesta amb força tant en aquesta novel la històrica com en la precedent i, en general, per tota la producció lozaniana. Aquest irromp des de les seues fileres embruixant el lector amb la gràcil veu d'uns mots exquisidament triats per a expressar sentiments, emocions, per a descriure fets o situacions, o simplement per a dur a terme la tasca de contar. Aquesta herència de la incursió de Lozano en el món poètic és treta a la llum voluntàriament per l'autor per a donar, fins i tot, un contrapunt a la cruesa dels fets relatats.

\section{Fonts etnopoètiques i folklòriques en la novel 1a històrica de Josep Lozano}

Un dels comentaris que s'ha fet amb més força respecte de l'obra de Josep Lozano des dels seus inicis literaris és la riquesa de la llengua que empra, on exalça la seua pròpia variant valenciana amb un alt grau de perfecció i de fidelitat. Crea tot el seu món literari en base a un model de llengua genuïnament valencià, i sobre la base d'un imaginari popular igualment valencià i això és el que comprovem en les dues novel les històriques que ara tractem però també en la resta de la seua producció.

Ens referim a diverses fonts etnopoètiques (cançons o llegendes) així com elements folklòrics (creences, costums, jocs...) que sobten el lector i el fan connectar amb aquell món perdut que vol recuperar l'autor: l'afany per no deixar en l'oblit tota aquella cultura beguda dels avantpassats que caracteritza els valencians, i que resulta indestriable de la llengua que la codifica.

En primer lloc, si parem esment a les llegendes és imprescindible tindre en compte una figura tan important per a la societat valenciana com és sant Vicent Ferrer: orador de masses, transmissor de profecies, persona canonitzada com a sant i, per tant, autoritat, però també protagonista de miracles esdevinguts llegendes. Per aquest motiu Lozano, àvid a captar totes aquestes fonts etnopoètiques que poden fer veure al lector quina és part de la cultura de la qual parteix per a recrear les seues 
trames de manera versemblant, no escatima, per exemple, a mostrar dos miracles efectuats pel sant valencià dins d'El Mut de la Campana:

\begin{abstract}
Després l'arxiprestre, un beneït papaneules, expressant-me el sentir dels festers, o per seguir el costum, va invitar-me a dinar en un lloc molt amé, fora vila, la font de Sant Vicent, on tot el poble anava cada any en romeria per celebrar el miracle que hi havia tingut lloc al segle xv. Perquè allí sant Vicent Ferrer havia fet brollar un gran doll d'aigua de davall una matiua d'olivera, després d'un llarg temps de sequera extrema que havia agostat les collites de la comarca (Lozano 2003: 163).

-Hom diu que l'any 1600, quan hi hagué pesta a Xàtiva, que després es va escampar per la rodalia, el nostre sant Vicent Ferrer aparegué miraculosament a València dalt del portal del seu nom, que és per on entren a la ciutat els que vénen de terres de migjorn, i va detindre la malaura. Però en el cas actual sembla que el nostre patró no ens haja assistit. Per tant haurem de breguejar per destruir-la (Lozano 2003: 214).
\end{abstract}

Sant Vicent Ferrer, ja s'hi ha apuntat, s'erigeix com un representant de la religió catòlica i, a més, de la via més ortodoxa. És en aquest sentit que també trobem en la producció de Josep Lozano altres llegendes i històries extretes o relacionades amb la religió cristiana en contraposició a llegendes extretes o bé connectades amb la religió islàmica. Trobem, així, dins del primer grup, llegendes sobre la figura de la mula al Betlem, la història d'Abisag i el rei David en la novel ta històrica de Crim de Germania o el perquè del nom de la Santa Creu en una casa de novicis esmentat en El Mut de la Campana.

Pel cantó de les cançons populars, n’hi ha diverses i la següent que mostrem és un exemple clar de com se celebra la vida per part dels valencians en relació amb la declaració d'amor d'un home a una dona:

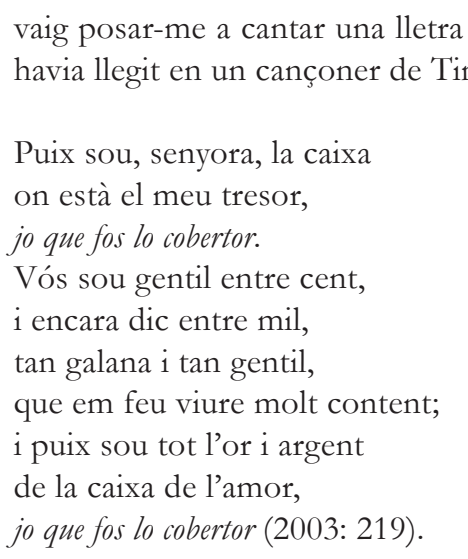

Ara bé, també cal ressaltar altres elements que participen d'aquesta cultura. Però ja no dins de la branca concreta de l'etnopoètica sinó dins del gran calaix que esdevé el concepte folklore. ${ }^{6}$ Així, un

6 En la introducció a l'obra A què juguem? Els nostres jocs i joguets tradicionals, Gisbert aporta unes pinzellades encertades sobre la noció de folklore: «la paraula floklore significa 'saviesa del poble'. Com diu Joan Soler $(2001,25)$ : «En un sentit ampli, la noció de cultura popular inclou el conjunt de mites, creences, sabers, institucions socials, tradicions, costums 
dels trets que ens sorprèn de la producció de l'escriptor és la dèria que demostra per la concreció en determinats moments de quins són els aliments que es cuinen o quins plats es preparen. És possible, per tant, conformar tot un grup de referències a l'alimentació i a la gastronomia que els valencians han anat ingerint al llarg del temps. Som allò que mengem, i ho som bioquímicament, però també culturalment. Ja ho deia el filòsof alemany Ludwig Feuerbach: «Der Mensch ist was er isst» (L'home és allò que menja) (1850). Altrament dit: la gastronomia és també un component essencial del folklore, de la cultura, de la idiosincràsia d'un poble. En les dues novel les històriques de l'autor les èpoques d'ambientació condicionen que la manipulació d'alguns aliments siga diferent a l'actual, tot i que els ingredients no deixen de ser els mateixos en gran mesura:

em cuinava pinsans, guatles, francolins i perdius que caçava amb paranys; em feia sopes de pastor, herba de conillets adobada amb oli i sal, cama-roges i lletsons fregits amb pinyonets, o gaspatxos amb carn de llebre que li eixien boníssims (Lozano 2003: 78)

Però els diferents aliments i menjars poden marcar, a més, la disparitat d'estatus social que es pot donar entre els personatges. Per exemple, en el memorable capítol «El banquet», de Crim de Germania, la virreina Úrsula Germana de Foix prepara un gran àpat, ple de plats exclusius per als seus convidats, també procedents d'un estament elevat de la jerarquia social com és la noblesa:

\begin{abstract}
Al forn es courien tota mena de llepolies: volves d'amor, artalets, canyelons, fogasses, tortells, gingebres, flaons, padous, casquetes, pinyonades, neules i coques fines.

El coc prepararia, a la gran cuina del palau, un cert nombre de viandes exquisides: polls tendres a l'ast i a l'aiguarròs, guatles, tartugat, vedells de llet, perdius, polls prenys, francolins, tórtores, colomins i moltons primals; així com carn de caça: cabirols, cérvols i cabrons monters.

Hi hauria fruita de tota llei per a les darreries: gínjols, cidres, magranes, pomes i carabassa al forn (Lozano 2006: 28).
\end{abstract}

En contraposició, mitjançant els aliments s'arriben a veure les penalitats que han de passar alguns dels personatges per poder sobreviure en el context i època en què són emmarcats, com és el cas de Felip Quzman que menjava rates:

Rates que deixàvem sis dies amerades d'oli perquè la carn s'ablanís i la poguéssem pair. Aquests eren els nostres queviures: rates, garrofes, algun grapadet d'ordi i algun tassal que, de tant en tant, furtava la cuinera del ben proveït rebost de la casa dels Maquefa (Lozano 2006: 221).

Una altra part important de la recreació de la cultura popular que Josep Lozano té en compte és aquella referida a les festes, tant lúdiques com religioses. Mitjançant aquestes ens ofereix la

i formes de vida materials i espifestis, els comportaments [...], els símbols i els valors, els ritus i les festes d'una col lectivitat, d'una comunitat». Rossend Serra fila més prim en definir-la com el conjunt d'allò que elpoble diu (rondalles, expressions, formes de parlar...), allò que el poble fa en la vida quotidiana (costums, jocs, festes...) i allò que el poble creu (mites, creences, supersticions...)» (2012: 8). Vegeu també Oriol (2002). 
possibilitat de conéixer de més a prop com els valencians manifesten l'alegria, la manera de divertirse o la devoció, i així comprovar què és important per a poder celebrar la vida.

No obstant això, cal remarcar que en aquest apartat són molt més abundants les referències a festes religioses que no a lúdiques: un fet, aquest, que ens condueix a la idea que l'autor, a pesar de saber limitar-se en cadascuna de les seues obres a l'època d'ambientació, vol mostrar el pes d'una herència assumida des de temps passats a propòsit de la religió cristiana. Tot el cicle vital dels valencians és condicionat per una sèrie de dates concretes en què se celebra alguna festa en remembrança dels actes «especials» realitzats per sants o santes, per les diferents versions de la mare de Déu o per Jesucrist.

Ara bé, sens dubte aquestes festes religioses, tal com insinuàvem, condicionaven i condicionen la vida de les persones pel que fa a la temporalitat dels anys. Aquest és el motiu pel qual moltes d'aquestes festes serveixen com a guia dins del calendari i resulta interessant comprovar que mentre en Crim de Germania i El Mut de la Campana resulta ben habitual l'ancoratge temporal per mitjà de festes en honor a figures bíbliques; només excepcionalment hem pogut constatar el mateix recurs en les narracions ambientades en el segle xx. A tall d'exemple, dins de Crim de Germania s'esmenta el dia de sant Jaume com una data que marca un fet important per als agermanats ja que és el dia en què vencen els mascarats en una batalla: «quan el dia de Sant Jaume, d'enguany passat, et vencérem prop de Gandia» (Lozano 2006: 202).

Per una altra banda, el simbolisme dels somnis en la narrativa de Josep Lozano també hi és important i uns casos que demostren a la perfecció aquesta idea és, per una banda, un en què el mateix dia d'una festa religiosa, la de Sant Silvestre, Antonio Navarro, àlies el rei Encobert, té un somni i en fa una interpretació que afectarà el seu mode de veure's. O també hi entraria el somni que té el virrei Hurtado de Mendoza abans de la batalla contra els agermanats. El comte de Cocentaina li insistia perquè li contara el somni que havia tingut i aquest així ho va fer, amb l'apunt de considerar que potser el somni tenia algun significat. Tampoc no podia faltar en aquest apartat la força que tenen els somnis en l'obra El Mut de la Campana en relació amb el seu protagonista. I és que Bernat Crestalbo té un somni que, curiosament, es repetiria durant set nits:

vaig somiar amb una vara gruixuda, resseca, suspesa al centre d'una gran tempesta, amb trons, llamps i aigües en abundància. En acabant la veia al final d'un bell camí, i com de la dura escorça naixien capollets de satalia, que esclataven en precioses roses (Lozano 2003: 51).

A més, cal advertir, que en la producció de l'autor alginetí són abundantíssims els elements que beuen del folklore i que remeten a creences i costums populars propis dels valencians. Ara bé, de vegades són creences i costums prototípicament genuïns, $i$ de vegades es barregen amb els d'una altra tradició molt present a terres valencianes, com és el cas de la cultura àrab. La diversitat hi és assegurada i aporta versatilitat i riquesa a l'obra lozaniana. Per exemple, en el cas següent es parla de la creença que quan una persona mor la seua ànima sempre escapa del cos: «i se sentí, de bell nou, 
un altre soroll; mai no sabré si fou una ventositat que eixia del meu cos o l'ànima del condemnat que, no podent sortir per la boca, perquè li ho impedia el dogal, sortia pel ses» (Lozano 2006: 240). $\mathrm{O}$, en aquest segon cas es parla del fet que nàixer d'una determinada manera es creu que és senyal de gràcia:

\begin{abstract}
Vinguí al món a l'hora tèrcia, sense massa carn sobre els ossos, de peus, amb sarró al cap ${ }^{7}$ i la guia enrotllada pel coll, un pròdrom que segons diuen les llevadores sol ser signe de gràcia. La mateixa vesprada d'aquell dia, i per por que morís, vaig rebre les aigües del baptisme a l'església de Sant Salvador; fet pel qual segons contava la mare -potser perquè hom oblidàs que havia estat engendrat sent ella fadrina - ni tan sols vaig romandre tres hores sota la màcula del pecat original (Lozano 2003: 9).
\end{abstract}

Caldria ressaltar, a més, totes aquelles conviccions i costums que s'han anat assumint a partir de la perseverant influència de la religió, ja siga la catòlica ja siga la islàmica, totes dues veïnes dins del territori valencià, com s'ha comentat, i totes dues presents en l'obra de Josep Lozano. Especialment ho són en les novel les històriques, on es marca més la presència de moriscos. Així, dins de l'aurèola de la religió islàmica trobem, en Crim de Germania, per exemple, una creença sobre les possibilitats que hi ha en l’altre món:

En aquell instant em vaig dir per a mi que, tant si anava a la jahanna, on els condemnats mengen la fruita amarga de l'arbre de zaqqum, com si era digne de la Glòria de l'Hort de Ruwbat, m'apoderaria de l'arracada; perquè millor servei em faria a mi que no a Rodagarberes (Lozano 2006: 240).

Però, per un altre costat, hi ha creences i costums populars que es poden associar a l'ús de determinats elements simbòlics que permeten celebrar algun tipus d'esdeveniment, com ara la pólvora, les rametes d'olivera o la palma -element imprescindible del Diumenge de Rams. Altres elements que també configuren costums populars serien, per exemple, el fet simbòlic de sembrar les terres de sal; o l'ús de la cendra simbolitzant el dol, prevenint qualsevol mal o com a part de la imatge d'una persona ja traspassada que vol demostrar la humilitat i l'actitud penitent.

Un altre ritual que s'explica amb deteniment és el de la mort, un tema ineludible en la producció de Lozano: «la mort, cuc filaner, anava encerclant-la teixint sobre ella un capoll de xàvegues finíssimes»

\footnotetext{
7 Gisbert explica succintament la significació de nàixer amb sarró: «Nascuts amb camiseta o surró: es diu dels xiquets que naixen embolicats amb un vel -la placenta-, sense trencar-lo, els quals tindran bona sort. Es pensava que la camiseta aportava una protecció contra les adversitats de la vida» (2008: 238). A més, aclareix com es llevava aquest sarró i què se’n feia: «Existien una sèrie de llaços entre l'infant i la placenta, per a bé o per a mal. Si es tirava a l'aigua, el xiquet podia morir ofegat; si es trencava posteriorment, podia emmalaltir o morir. Per aquesta raó, solia actuar-se de dues maneres: o bé s'enterrava o es destruïa, tallant-la; o bé es guardava, perquè el xiquet tinguera sort durant tota la vida. Fins i tot hi havia casos en què actuava d'amulet, quan el jove havia de fer el soldat per tal d'evitar que morira de bala (Duque 2003, 39)» (2008: 238).
} 
(2006: 33). Els ritus mortuoris han canviat amb el pas del temps perquè la vida i, per tant, la mort, ja no es gestionen com en temps anteriors. I, de fet, aquesta diferència és la que se subratlla en les obres de Josep Lozano, que no volen deixar escapar l'oportunitat de mostrar com s'ha anat tramitant al llarg dels segles qualsevol faceta vital que afecte l'ésser humà. És per això que, a pesar dels canvis d'ambientació entre, per exemple, la novel la històrica El Mut de la Campana i l'obra Ribera (dels anys noranta, amb forta presència del context rural), els ritus mortuoris són molt semblants: combregar i pernoliar el cadàver, llavar-lo i amortallar-lo.

Per últim, podrien ser tinguts en compte aquells ritus que es fan en ocasions ben determinades, com ara fer sanar alguna malaltia o alguna part del cos que ha quedat adormida, com s'esdevé en el cas de la virreina Úrsula Germana de Foix: «Després, per tal que li passàs, com un ritu quotidià, es va posar l'índex de la mà dreta a la boca, i amb un poc de saliva féu tres creuetes damunt de la vestimenta, a l'altura de cada genoll» (Lozano 2006: 31).

Finalment, per cloure aquest repertori de creences i costums populars, caldria parlar del simbolisme, ara en relació amb els números i la màgia que sempre han representat: una màgia, això sí, que beu en gran part de la religió. Per exemple, en relació amb el número tres hi ha un capítol de Crim de Germania que en gira al voltant i que té, en aquest sentit, un títol molt significatiu: «El Senyal Evident o la Prova Clara». Es tracta de la venjança d'un fill per la mort de son pare a través de tres panses -i el número, lògicament, no és aleatori- que tenia aquest enclaustrades en la seua mà una vegada ja mort. I, de fet, en la narrativa de Lozano aquest número tres també apareix en altres moments, com en un moment crucial de la novel la històrica El Mut de la Campana, concretament quan el protagonista sent tres vegades el so de la campana del Mut que l'empentaren definitivament a tallar-se el seu membre viril (Lozano 2003: 305-306).

Però, en canvi, hi són molt més abundants les referències a jocs populars comentats o executats per part dels adults. Resulta curiós com aquest apartat dels jocs populars no afecta de cap de les maneres l'època d'ambientació de les obres perquè d'una forma o altra, en l'univers lozanià són sempre presents i perduren -per dir-ho així- al llarg dels segles. És la manera d'expressar una forma de viure - «Que en la vida, com en el joc» [...] «la nostra planeta barreja les cartes, i nosaltres no tenim més remei que jugar-les» (Lozano 2003: 11). Així, veiem en el cas següent la quantitat de jocs que s'esmenten, com a propis i genuïns de la cultura valenciana: «Que en aqueix tèrbol món dels naips o cartetes, travesses i daus, tenia fama de jugar-se a la taverna dels Trucos, en el joc del renegat o als cientos, el sol abans de nàixer, balafiant els pocs diners que tenia» (Lozano 2003: 11).

Tot aquest cúmul d'elements referents al folklore que estem comentant i analitzant el tanca la secció de les malalties, per una banda, amb el seu contrapunt dels remeis populars, per una altra. En tot moment hem vist que la societat valenciana celebra la vida o simplement l'expressa. Però la mort és l'altra cara de la vida i, tot i que s'ha vist en certa manera mitjançant els rituals mortuoris explicats, en aquesta ocasió examinarem més a fons la manera en què el novel lista alginetí recrea en les seues ficcions literàries les malalties que podrien amenaçar la continuïtat de la vida. 
Lògicament, igual que passava anteriorment, les dues novel les històriques són els principals brolladors de malalties diverses que, òbviament, condicionaven els estils de vida. Ara bé, adés hem explicat que els remeis populars esdevenen el contrapunt a aquestes malalties, ja que es feien per tal de guarir-les però sempre d'una manera peculiar. Fet i fet, tant la concepció popular de les malalties com alguns dels corresponents remeis, de vegades s'adscriuen més fàcilment a la història cultural i etnològica -quan no, directament, a la superstició-, que no al rigor de la medicina i les catalogacions patològiques actuals. Així, trobem la focalització de determinats remeis esparsos, com ara sanar malalties, curar emmetzinaments, aturar la pesta o fer avortar: «perquè hi guardava [al bagul] els seus coberts, algunes espècies per adobar guisats, i també, segons les enraonies de les criades, un trosset de banya d'unicorn, poderós antídot contra tota metzina» (Lozano 2006: 230).

Tota aquesta anàlisi que acabem de testimoniar era necessària per a poder albirar la totalitat de l'element cultural dins la producció de l'escriptor. És només d'aquesta manera com podem entendre el projecte literari de Lozano, amb quines eines compta, i fins on arriba. Un projecte, aquest, que es guia per l'objectiu -ambiciós alhora que ètic- de crear ficció de qualitat però també recrear una llengua, una cultura $i$, en definitiva, un poble.

\section{Conclusions}

La crítica literària va rebre en el seu moment Crim de Germania com una obra innovadora, que donava un nou alè a les lletres valencianes pel tractament reivindicatiu de la temàtica de les Germanies, així com per l'ús d'un llenguatge sublim que apropava el català del segle xvi sense abandonar la intel ligibilitat. A pesar d'algun retret cap al monòleg del cabdill Vicent Peris en el capítol titulat «La mort de Vicent Peris» o de la controvèrsia de la seua adscripció a un gènere -on apostem, com fan molts, per etiquetar-la com a novel la històrica-, l'obra ha estat lloada de manera unànime. I ha estat així fins a la mateixa actualitat, sobretot després de la reedició de l'obra per part de l'autor l'any 2005 en què incorporava dos relats més i en absoluta consonància amb la guerra de les Germanies que tracta l'obra i que referma la seua coherència.

El Mut de la Campana, per la seua banda, suposa el retorn de l'autor a l'àmbit de la novel la després de dotze anys de silenci en aquest sector a causa de les seues pròpies exigències com a escriptor -i ací entra el perfeccionisme que el caracteritza- unides a les pròpies ocupacions laborals, ja que la literatura mai ha permés Lozano viure de l'escriptura. Aquesta obra ha estat exaltada per la crítica per ser la continuadora de l'estel de la novel la històrica malgrat que amb objectius i temàtiques diferents. Se li ha lloat la gran tasca de documentació que hi ha al darrere així com fer possible una llengua comprensible per al lector actual. Tanmateix, també ha rebut alguna crítica negativa pel que fa al final de l'obra i, com passa amb la resta de la producció lozaniana, no pot superar el bon acolliment general de Crim de Germania. 
El que queda clar és que aquesta línia de la narració històrica aconsegueix, per la via de la unió entre ficció i història, traure a la llum passatges que afecten l'evolució de la societat valenciana, tant en un intent d'alliçonar com en un intent d'informar. Així mateix, és la manera com l'autor retorna la dignitat a la llengua catalana, palesant la seua riquesa i ductilitat, a través d'unes trames coherents, ben documentades i travades.

Tanmateix, l'autor s'ha mostrat ferm a l'hora de plasmar per escrit allò que li interessava -ell mateix s'ha declarat lliure de modes i sí fidel a la intuïció pròpia- i és en aquest sentit que no es pot deixar passar el fet que allò que li interessa és retratar la societat valenciana de la qual forma part. Crim de Germania és, per a tal afer, una obra clau ja que, com déiem més amunt, s'hi aprofita la història, el passat, per a conéixer el present. Però és més: en el cas del col lectiu dels valencians s'aprofita aquest passat també per a entendre el present més particular, en què hi ha una lluita que des de les Germanies continua per la defensa d'una cultura, d'una llengua i d'una identitat pròpies.

Comença, així, Lozano, a alçar la seua veu com a valencià i, a més, un valencià escriptor -i, per tant, públic, amb les possibilitats que això comporta- per poder fer entendre als possibles lectors què hi ha hagut sempre en joc. Ja des de bon inici, per tant, el seu projecte literari no s'entén sense una vessant cultural i combativa. Per tant, enmig de les pàgines que crea deixa caure un sentiment de pertinença a un col lectiu que repercuteix en el sentiment d'identitat. Aquesta idea reforça el seu projecte nacional i, encara que l'exemple següent està extret d'El Mut de la Campana que ja no tenia les intencions de Crim de Germania, deixa veure clarament el que diem:

Perquè, al capdavall, aquesta és la meua terra [València], en les hores bones i en les hores dolentes, on he viscut, he amat $\mathrm{i}$ he sofert, i talment com el meu avi estimava el seu poble d'Alèdua, també jo estime la meua ciutat i ací vull morir-me (2003: 308).

Aquest sentiment de pertinença també es vehicula, i d'una manera, si potser encara, més contundent, mitjançant les fonts etnopoètiques i folklòriques que es poden rastrejar en l'obra lozaniana. I és que una ullada a aquestes fonts des de la vessant de la narració històrica ha confirmat que al darrere hi ha tot un programa cultural que, difícilment, no connectaria amb un públic lector.

En definitiva, analitzar la novel la històrica de Josep Lozano no només ens ha fet albirar el treball minuciós que ha esmerçat al llarg de la seua carrera a crear un univers narratiu ric, i sobretot compacte i ben travat, sinó conéixer que aquesta ficció narrativa amaga molt més que un treball de creació -sense desmeréixer aquest, com ja s'ha remarcat. Al darrere hi ha tot un programa cultural que intenta aprofitar l'ocasió per a exalçar la força intrínseca d'una societat com la valenciana, però no d'una manera directa - tot i que de vegades semble que sí, com en Crim de Germania- sinó com una pell que està sota tota la producció i que sura en els moments oportuns. Aquest maridatge entre creació literària i aprofitament de la cultura popular pròpia donen com a resultat un projecte literari ambiciós i combatiu, que busca literaturitzar tota una societat des de la vessant de la narració 
M. Jesús Francés. La novel la històrica en mans de Josep Lozano: Crim de Germania i El Mut de la Campana

històrica -així com des de la resta de la seua producció narrativa encara que ara no la tractem- ${ }^{8}$ per a mostrar com és però també per a fer veure què la identifica. Amb aquest estudi, per tant, pretenem posicionar la figura de Josep Lozano en el lloc que mereix dins d'un gènere com és el de la novel la històrica i emmarcat al territori valencià.

\section{Bibliografia}

Feuerbach, L. (1850) Blätter für Literarische Unterhaltungs, Leipzig (12-XI-1850).

Francés, M. J. (2011) «El Mut de la Campana: l'autobiografia com a ficció», dins Espinós J./ Escandell D./ Marcillas I./ Francés M. J. (eds.) (2011), Autobiografies, memòries, autoficcions, Catarroja-Barcelona, Afers, p. 285-296.

- - (2012) «El Barroc a través d'El Mut de la Campana de Josep Lozano» [en premsa].

. (2014) «Sant Vicent Ferrer i la religiositat barroca: El Mut de la Campana de Josep Lozano», dins Fàbregas, I. / Alonso, A. / Lagarde, C. (eds.) (2014), Els Països Catalans i la Bretanya a l'Edat Mitjana: entorn de la matèria de Bretanya i Sant Vicenç Ferrer, Perpignan, Trabucaire (Collection Culture catalane/Cultura catalana), p. 183-196.

Garcia Grau, M. (1997) «Notes sobre Crim de Germania de Josep Lozano», Passadís. Quadern de Lletres, núm. 18, p. 29-44.

(2015) L'obra narrativa de Josep Lozano: textos, contextos i referents etnopoètics [Tesi doctoral defensada el 29/09/2015 i consultable en http://rua.ua.es/dspace/handle/10045/51025?locale=ca]. 8 Per a més informació, consulteu la nostra tesi doctoral titulada L'obra narrativa de Josep Lozano: textos, contextos $i$ referents
etnopoètics, defensada al setembre de 2015: http://rua.ua.es/dspace/handle/10045/51025?locale $=$ ca. 
M. Jesús Francés. La novel la històrica en mans de Josep Lozano: Crim de Germania i El Mut de la Campana

Gisbert, F. (2012) A què juguem? El nostres jocs i joguets tradicionals, Picanya, Edicions del Bullent.

Gregori, C. (2013) «Introducció», dins Lozano, J., Després de les tenebres i altres narracions, Alzira, Bromera, p. 7-24.

Iborra, J. (1980) «Crim de Germania per Josep Lozano Lerma», Serra d’Or, 252 (setembre 1980), p. 39.

Lozano, J. (2003) El Mut de la Campana, Alzira, Bromera.

- (2006) Crim de Germania, Alzira, Bromera (Col lecció «Els nostres autors») [la 1a ed. (en Josep Lozano, Crim de Germania, Alzira, Bromera (Col lecció «Els nostres autors»)) és de 2005].

Oriol, C. (2002) Introducció a l'etnopoètica. Teoria i formes del folklore en la cultura catalana, Valls, Cossetània Edicions.

Piquer, A. (1997) «La coherència lingüística i l'estratègia discursiva en l'obra de Josep Lozano (una mirada didacticoliterària)», Passadís. Quadern de Lletres, 18, p. 19-28.

Salvador, V. (2001) «Estudi introductori», dins Lozano, J., Crim de Germania, València, Tres i Quatre (Col lecció «L’Estel»), p. 9-69 [la primera edició (en Josep Lozano, Crim de Germania, València, Tres i Quatre, (Col lecció «L'Estel»), p. 9-69) és de 1987].

Salvador, V. / Piquer, A. (1992) «Estudi Introductori», dins Vint anys de novel la al País Valencià, València, Tres i Quatre, p. 7-40.

Simbor, V. (1997) «Sobre la novel la històrica actual», Caplletra, 22 (primavera 1997), p. 105-128.

—. (2007) «Introducció», dins Josep LozAno, El Mut de la Campana, Alzira, Bromera, p. 7-22.

Sorribes, J. S. (1989) «Josep Lozano: Compromís i bellesa del crim», El Temps (16-10-1989), p. 93.

Tobar, F. (2004) «Josep Lozano: "La literatura és per a mi un espai de llibertat, però alguns llibres són un atemptat contra la massa forestal"», Caràcters, 26 (segona època-gener 2004), p. 7-8. 